\title{
THE EXPERIENCE OF LIVING WITH CHRONIC KIDNEY DISEASE
}

\author{
Claudia Andrea Ramírez-Perdomo
}

Department of Nursing University of Surcolombiana, Colombia. clauram1@hotmail.com

\begin{abstract}
Chronic kidney disease is a public health issue due to its high incidence, morbidity, mortality, and overload of health systems. It is a disease in which renal function is progressively lost. The aim of this study was to understand the experience of people living with Chronic Renal Disease who have received a kidney transplant. I used the hermeneutic-phenomenological qualitative research method proposed by Van Manen (2014). There were 11 participants with Chronic Renal Disease in this study. The main theme that emerged was the experience of living with chronic kidney disease. I grouped sub-themes as the existential lifeworld of: (a) Relationality: feeling stuck, Terminal Chronic Renal Failure and support; (b) Temporality: something unexpected, being present and not seeing it, being young and sick; (c) Corporeality: body deterioration and changes in sex life; (d) Materiality: the effects on the economic status; and (e) Spatiality: changes in life, sadness, and depression. This study represents an important tool for the development of selfcare models articulated within public health policies aimed at caring for people with Chronic kidney disease.
\end{abstract}

Keywords: Kidney Disease, Chronic; Kidney, Transplantation, Research, Qualitative, Hermeneutic.

\section{INTRODUCTION}

Chronic kidney disease (CKD) is a debilitating disease, caused by a gradual and progressive loss of renal function which affects the person and his surroundings (Gill, 2012). The number of people with CKD and Terminal Chronic Renal Failure continues to increase, being a public health problem that could reach severe epidemic proportions. It is estimated that, by 2030 approximately 2.2 million people in the world will require renal replacement therapy (EneLordache et al., 2016).

There are several important factors for the development of the disease including aging, cardiovascular diseases, and type II diabetes mellitus, considered to be responsible for its increasing incidence (Schaepe \& Bergjan, 2015). The main treatment options are kidney transplantation or dialysis. Given the limitations of kidney transplantation, it is recognized that most people enter renal replacement therapy (Schaepe \& Bergjan, 2015).

Studies have addressed this phenomenon and its effects on body image and treatment, mechanisms for surviving the disease (Campos \& Turato, 2010), and the adherence to treatment considering how various experiences and religious practices contribute to decision making (Lam et al., 2014). Coping strategies used to live with the disease and manage treatment such as dialysis are important elements that involve changes in patients' lives (Chatrung et al., 2015; Gill, 2012; dos Santos \& Valadares, 2013). 
Other related aspects include diet issues and changes in protein-calorie intake, which cause an increase in malnutrition during the initial stage of renal replacement therapies, leading to increased morbidity and mortality in these people (Palmer et al., 2015). Sabancogullari et al. (2015) address changes in the patient's sex life due to hormonal changes, symptoms associated with the disease and dialysis treatment, and the importance of decision making in relation to treatment modality.

This research generates novel elements. The studies above addressed the individual within their experience at some stage of the disease and treatment. This study sought to find answers in the meaning of the experience of people with CKD in an attempt to find a comprehensive view for the care of the person and his family. In this context, the objective of this study was to understand the experience of people living with Chronic Kidney Disease who have received a transplant. The research question guiding this study is: How can the meaning of the experience lived by people with chronic kidney disease contribute to improved care practices that nursing professionals provide to these people?

\section{MATERIAL AND METHOD}

This is a phenomenological hermeneutical qualitative study (Van Manen, 2014). Consistent with this perspective, I sought through a face-to-face inquiry to reconstruct the meaning of the experience lived by people with CKD. I explored the socio-personal environment to understand more deeply their experience and derive from the knowledge obtained a set of guidelines that would allow improved the care for people who have this health condition.

I collected data through face-to-face interviews. I began analysis upon transcription of the interviews following Van Manen's method, in six steps: 1) collection of lived experience; 2) reflection of lived experience; 3) reading and rereading of interviews, 4) recovering the semantic language within the text, 5) detection of emerging issues, 6 ) writing and rewriting of the lived experience (Van Manen, 2014). I centered the analysis on the existential lifeworld (Van Manen, 2014). This includes five components:

1. Relationality identifies the relationships that people maintain in their shared space. It leads to reflection on how relationships can influence the perception of the phenomenon, recognizing common features in the other, and the social components that give meaning to life (Van Manen, 2014).

2. Corporeality is the immersion in the corporeal world. Here, things are consciously or unconsciously revealed or hidden in the encounters with other people. One's body language 
changes during these encounters which allows us to identify how the body experiences, feels, perceives, and manages a phenomenon (Van Manen, 2014).

3. Spatiality in which space is interpreted as having Cartesian properties with universal coordinates and distances, but the interest is about how space is felt and gives meaning to the phenomenon (Van Manen, 2014). Heideggar (1974) explained, "the spatiality of man is something inseparable from his corporeal being ... 'grounded' in his corporeality" (p. 70).

4. Temporality is examined in relation to how time is experienced and is correlated with a subjective time. The meanings of an experience with time are interpreted at a particular time (Van Manen, 2014).

5. Materiality concerns how things are experienced and describes how "intramundane or useful bodies" assign a meaning (Heidegger, 1974; p. 68).

The 11 participants in this study were all CKD patients who had received kidney transplants and residents of the city of Neiva, Colombia. I selected them by casual sampling, considered to be the most formal in qualitative research (Patton, 2002). This sampling method requires the researcher to review and study all cases that meet the predetermined criteria, ensuring the quality of the data (Patton, 2002).

Through this process, the participants provide representative information (Patton, 2002). It is not problematic that I did not use random sampling methods as participant selection was guided by specific participation criteria.

Additionally, I chose participants from the database provided by the South-Colombian transplant unit. Inclusion criteria focused on participants who were people with transplanted CKD, were older than 18 years, had a renal transplantation for the first time for a period greater than six months, or were re-transplanted with for a period greater than six months.

I collected data from December 2015 to January 2017. I initially contacted participants by phone. All of those contacted agreed to participate and the author had no connections with these people. I used in-depth interviews to collect data.

After the initial phone contact, I interviewed participants in a face-to-face format at their residences, starting with the following question: Can you tell me about your experience since you were diagnosed with CKD? I expected this question to be broad enough to allow the participant to speak without restraint. 
I followed a list of questions encouraging elaboration that allowed them to reflect deeply on the phenomenon. The interviews lasted 60-90 and were recorded, listened to, and transcribed in full by myself.

The Ethics Committee of the University of Antioquia approved the study (Document \#CEIFE2015-05).

I considered the Resolution 8430 of 1993 and the ethical principles of beneficence, autonomy, privacy, freedom of expression, and sentiments. In the case of qualitative research, the researcher builds, collects, selects, and interprets the data. Reflexivity has an important role in this approach.

Reflexivity is the process of connecting within the research based on introspection of personal and professional experiences, knowledge, and interest in the phenomenon of study (Finlay, 2002).

I considered credibility and the possibility of obtaining confirmation, achieved through textual transcription of the interviews by the researcher.

Other qualitative research experts reviewed the findings of this study. I also returned them to the participants for member checking (Lincoln \& Guba, 1985).

Regarding transferability, I expect that the results of this study serve to find similarities or divergences with the findings of other studies addressing the phenomenon.

\section{FINDINGS}

This article addresses the theme of living with chronic kidney disease. Figure 1 below shows the relationship between this existential lifeworld and the sub-themes, allowing the reader to recognize this experience is a network of relationships and not a series of events that take place during the life of human beings, a concept consistent with the hermeneutical phenomenology. In what follows, these sub-themes are described and illustrated with sections of the interviews. 


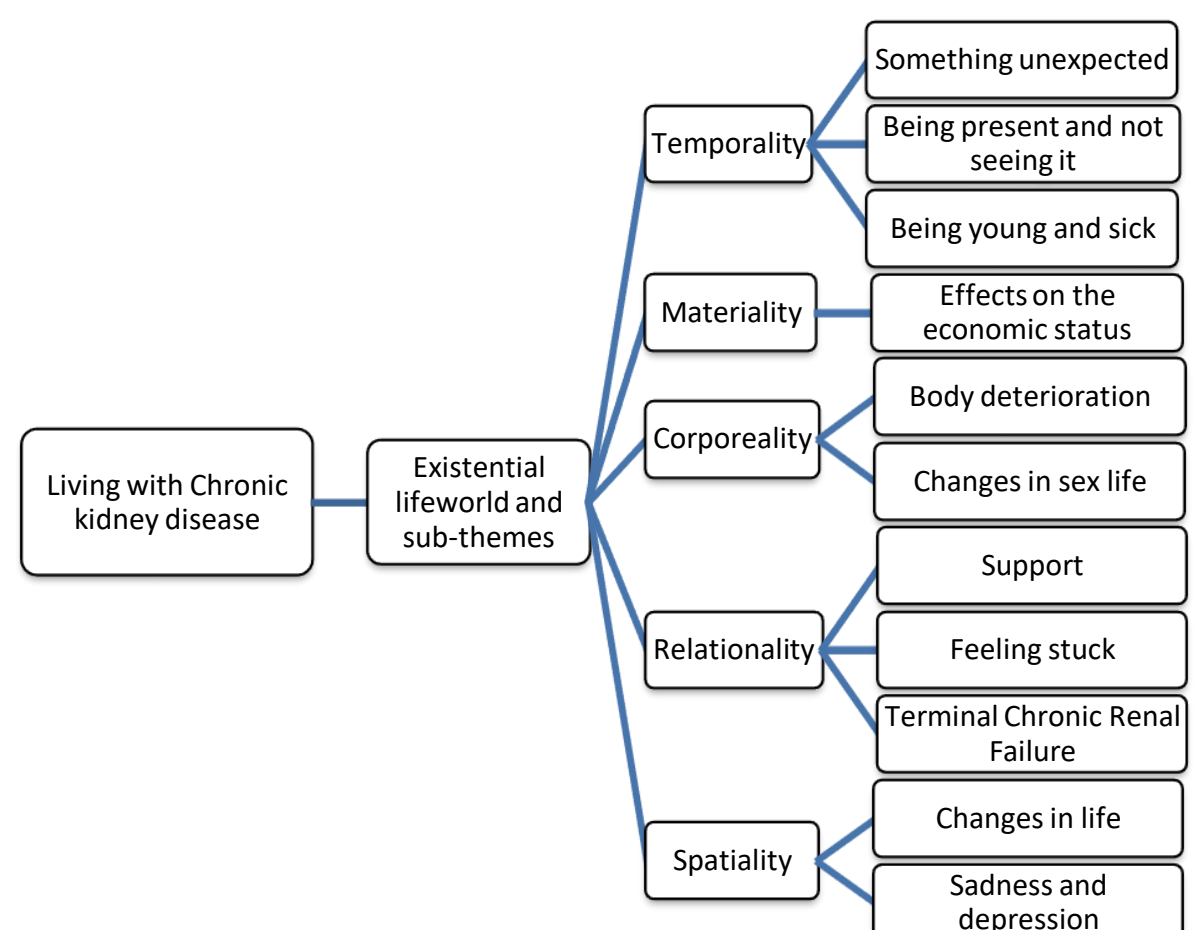

Figure 1. Relationship between the Existential Lifeworld and Sub-Themes

Table 1 below presents the demographics the participants in the study. They are all residents in Neiva. There were 5 men and 6 women. The minimum age was 20 years and the maximum was 70 years. Six had received peritoneal dialysis and hemodialysis. Four had received only hemodialysis. One had received peritoneal dialysis only.

Table 1. Demographics of Participants, Neiva, Huila, Colombia 2015-2017

\begin{tabular}{lcrll}
\hline Pseudonym & Gender & Age & Education & Type of treatment \\
\hline MMV & F & 20 & Technical & Hemodialysis and Peritoneal dialysis \\
JIB & M & 27 & Secondary & Hemodialysis \\
VG & F & 28 & Secondary & Hemodialysis \\
EP & M & 37 & Secondary & Hemodialysis and peritoneal dialysis \\
EYS & M & 39 & University & Hemodialysis and peritoneal dialysis \\
MCV & F & 42 & University & Peritoneal dialysis \\
MAA & F & 50 & University & Hemodialysis \\
MEA & F & 52 & Secondary & Hemodialysis and peritoneal dialysis \\
MR & F & 62 & Basic education & Hemodialysis and peritoneal dialysis \\
JCC & M & 69 & Basic education & Hemodialysis and peritoneal dialysis \\
AS & M & 70 & University & Hemodialysis and peritoneal dialysis \\
\hline
\end{tabular}




\subsection{Relationality}

As characteristics of relationality, participants acknowledged support, feeling stuck, or Terminal Chronic Renal Failure.

\subsection{Support}

When discussing support, I identified two sub-themes, these being support from friends and family support. Support from friends can occur in different ways. The first is at the economic level in ways such as providing housing, helping with food, or collaborating at work, making participants feel supported and that they can trust their friends. They shared news related to their transplant with these persons and requested their collaboration to help solve different situations that may arise. They transformed their companionship into a way of understanding that "life is not over," that they were still alive and, therefore, they must move forward in life, accompanied not only by the disease but also by people who are there for them. Participant EYC said:

I called some friends. I told them "I will probably undergo the transplant." I took some money and went to the airport. When I came to live with my friend and his wife ... she used to cook the food without salt, I took out my food first and then she added salt for everyone, they used to take care of my diet.

MCV explained:

My roommates arrived, a blessing, the companions of admitted patients and they gave me a lesson about life, because they always ask that, then they started talking about work, what happened at work, I kept looking at them and said: "Life is not over, I'm alive, with this disease, but still alive."

Regarding family support, participants indicated it was crucial to feel accompanied and protected, with the perception of being cared for. The intervention of the family, at this stage, gave them an impression that their problems diminished, helped them cope with the disease, and facilitated the adaptation process. They recognized the participation of their family in the care of their diet, their economic and emotional support, as well as their participation in the treatment. In this way, they realized that the disease is not a process that is lived alone, but it involves all family members, making them indispensable pillars for the person to overcome the disease. 
MEA mentioned:

The disease belongs to the two, three, four of us, it is not only mine; it also belongs to my husband and my children. The young partner wants the disease to be experienced only by his wife, but the affected person needs support from others to overcome the disease, it is vital having the family on their side. If you do not have family support, you have a relapse, and it happens quickly; if the husband does no support her wife, she will not accept her disease, she will not accept living with the disease ... and then Goodbye... this is the main cause, not accepting the disease.

\subsection{Being stuck}

The disease leads participants to feel stuck because they had difficulties with travel, going to work, and attending leisure activities. The feeling of being stuck ws described in their statements wen they explained that they were excluded from many activities because the disease limits the possibility of carrying them out or they had to be postponed. They also experienced fear of the possibility of making a trip or their inability to work because they feel stuck. AS noted:

One feels stuck... I had the opportunity to go abroad because I have a daughter who lives in another country, but I do not want to travel now, I'm afraid that I will get sick there... I am afraid of having a urinary tract infection or something like that.

\subsection{Terminal chronic renal failure}

The participants expressed the terror they experience when they hear the words "terminal chronic," in reference to the disease stage in which they are, since they have the feeling of approaching death. EP said:

It causes terror because when they say "there's nothing left to do." The word terminal means "it is not working anymore," "you are going to die." People have an impression that they say terminal because AIDS, cancer and brain death are terminal illnesses, then, the affected aspect is the psychological one.

\subsection{Temporality}

Temporality for the participants means something unexpected; chronic kidney disease was a surprise. They described the disease manifesting as a breakdown of everyday life. 
The disease appears at a moment's notice and the affected persons experience symptoms such as vomiting, adynamia, diarrhea, and edema. Often, they visited a doctor's office or an emergency room without even imaging that they had chronic kidney disease, characterized by failure of kidney function. EP explained:

It all started when I began to exhibit symptoms... I began to feel sick, I had vomiting, diarrhea, a foul taste in my mouth, cramps, discouragement. Initially, everything I ate I vomited. I thought I had hepatitis, anemia, or some viral disease. I never imagined that I had chronic kidney disease.

Finding out that they had chronic kidney disease became a traumatic moment, which led them to "disbelieve" in what was happening.

This was because during their lives, they had been considered healthy people, and thus, this situation became an unknown experience. They considered this process as a hard and difficult situation to deal with, yet also described it as "for life." MCV said:

I had never undergone any surgery or suffered a fracture, so having to lead a difficult life and becoming aware of it at a moment's notice was a new, strange, peculiar experience to me, of course, something I had never imagined.

\subsection{Being present and not seeing it}

CKD becomes a battle against time. The disease announces its presence by sending alerts that are not detected early. Therefore, the diagnosis for participants was delayed for when the disease had been definitively established. MR noted:

That was hard, I was born with only one kidney and I just realized that at the age of $50 \ldots$ they performed examinations and found that I was born with only one kidney and I was working like a toad, slow, slow and that was hard... I was arriving late... That was how my battle began. It has been hard.

This problem had been present for a long time and warnings were presented, but they were not able to detect the warning signs.

The presence of associated diseases as possible triggering causes of this one are unknown and, only when they are evaluated by the doctor or undergo laboratory tests and receive the diagnosis do they try to establish the association between symptoms and the disease. Participants became aware of these symptoms after their diagnosis, but due to lack of knowledge, they were unable to identify them. 


\section{EYC indicated:}

I realized that the warnings were on, but I never paid attention. At that time, I remember that I drank alcohol on weekends and I did not feel like eating, I felt nauseous, I drank but I was not feeling well. "What's the matter?" "I do not feel like drinking, I do not know what's wrong with me, I have been feeling sick." I realized that this happened to me every now and then, but I did not notice anything else besides that.

\subsection{Being young and sick}

The young participants recognized age as a positive factor; it means that they have a lot of time to live. On the other hand, they perceived age as a factor that makes it difficult to take on their daily activities. They associated this with not being able to perform social activities appropriate for their age, such as going out to parties with friends, consuming alcohol, sightseeing, or going overseas. For example, VG explained:

One loses his youth... The phase at which people go out to drink or party... And I see my cousins, many of them are in the age that I started HD. They do different things, which I could not do... It is a phase that cannot be wasted... Young people want to go sightseeing... To enjoy the world...

At the same time, they had difficulty establishing social relationships with people of the opposite sex. They felt that, because they had this condition, no one paid attention to them and that they were not attractive enough to establish relationships that went beyond a simple friendship. This was why there were feelings of frustration, dissatisfaction, and rejection toward the disease and the treatment itself, leading them to states of depression. JIB said:

Sometimes I thought, "I am on dialysis to get a woman," but it is hard winning over a woman who looks at you like that. Besides, they are complicated, they use to say: "This sick guy..." I felt traumatized... depressed, and I used to think, "I'm so young and sick like this" I thought about many things.

\subsection{Corporeality}

The disease affects the corporeal form causing multiple transitions that must be resolved. In order to achieve this, it is important that there is a separation from the biomedical model, which approaches the body from the disease.

\subsection{Body deterioration}

CKD causes body deterioration, weight loss, changes the color of your skin, and abdominal bloating, which made participants feel insecure and fearful. They felt ashamed of their body, 
which prevented them from establishing relationships with others. The disease became evident in all its magnitude since it converts the body into an instrument that makes it appear with all its intensity, consolidating its presence in their lives. As MVV described:

I was embarrassed when they looked at me... They used to ask me... "what's wrong with you?" I was skinny and with a big belly, I was ashamed... I had been shy all my life... I used to think, "but why do they keep asking so much?" I did not feel like going out... I preferred to stay home.

\subsection{Changes in sex life}

Participants indicated that the disease affected their sex life. Feeling sick and being in treatment were factors that caused them to have difficulties in maintaining an active sex life. Their sex life changed, it simply reduced and they experienced a fear of not "functioning," associating this with uremia, drugs, comorbidities, or the presence of the peritoneal catheter. This caused them distress and despair, in addition to the aggravation of not being able to express their feelings of the situation or seek help to solve it. AS noted:

Regarding the experience of having sex, one remains discouraged, the disease and many medications affect the erection... Then one tries to lead the marriage as good as possible, but it is not the same anymore... I know friends who have problems in that sense, they do not express it because these are intimate things, and these are manifested during conversations when there are meetings. Let's consider that then these are expressed.

\subsection{Materiality}

Materiality means that things cannot be approached from the outside. On the contrary they need to be approached from the inside in terms of the type of presence that it has in dealing daily with them.

\subsection{Effects on economic status}

Participants' statements allowed for an understanding of the economic impact of the disease, as having to leave work or being retired for disability decreased their income. In addition, the increasing costs of travel and the need to assume the costs of treatment led them to perceive the disease as a difficult situation to overcome. MCV said:

Leaving my job cost me a lot. I was working, having to leave my job was the hardest part for me. I should have been earning a better salary and now I have a low income... Then it hurts, I do not earn as much as I should... It has been the highest cost due to the disease, I had to become a pensioner. 


\subsection{Spatiality}

In the experience of CKD, patients are not only part of the tangible space, but rather they invade the intangible space. This invasion makes them difficult to measure or establish limits since they are substantial aspects that constitute the plot of meanings attributed to the phenomenon of study.

\subsection{Changes in life}

The participants described the disease as "a splash of cold water." The disease led to changes in their lives, making them abandon their plans, adjust their lifestyle, adapt to a new situation, assume a new treatment, and make decisions. They felt as if life was over and they must awake to a hard reality, experiencing it as a surprise. In many cases, their lives suffered a heavy blow because they were primary economic support for their family. All this led them to rethink their situation, causing a role change, which had an impact on their lives in the economic, social, and affective contexts. EP noted:

It is very hard... It's like when one is awake and someone else throws a bucket of cold water on him. What happened? Where do I start? Where do I go? What do I do? What am I going to do with my life? Should I go, stop or stay?

\subsection{Sadness and depression}

The disease affected participants' emotional condition and they referred to moments ranging from not knowing what to do to suicidal thoughts.

They had feelings of despair and sadness, which sometimes led them to think about committing suicide. However, through the perceived support, reflection, and medication, they managed to overcome these feelings and move on, accepting the disease.

Loneliness and depression were factors that worsened the feeling of helplessness and the desire to end up lives in order to end the suffering they were going through. MCV explained:

It was hard in the first 15 days... I tried to commit suicide, and that story "it only happens to others," to want to die, it's true... I thought, "What now?" When I started to think about it, I decided to commit suicide. I opened the window on the second floor and was about to jump, but when I opened the window, I realized, "What am I doing? Forgive me, God." No, and then I realized that I was wrong, I was depressed, mainly because I was alone. 


\section{DISCUSSION}

Relationality allows for a reflection of how the person's relationships with others can influence the perception of the studied phenomenon, recognizing in the other the common and the social serves to give meaning to his life (Van Manen, 2014). In these data support, feeling tied, and terminal CKD take relevance in this existential.

Research results describe the importance of family and friends in caring for this disease in that that helps them move forward with their lives (Calvey \& Mee, 2011; Nagpal et al., 2017). Patients perceive the treatment as the central and essential axis of the activities of daily life, awakening in them feelings of discomfort and anguish for which they feel trapped in their world and lose their self-sufficiency generating a dependence on others (Lin, et al., 2015; Monaro et al., 2014).

Temporality is the experience in time, not the time of the clock or a chronological time, but the time in which the phenomenon is experienced (Van Manen, 2014). The past is the "pre," the future the "coming," and the present the "now" (Heidegger, 1974); therefore the subtopics something unexpected, being present and not seeing it, and being young and being sick, are recognized in their temporality. An unexpected, evolving disease in which life transitions can occur is abstract and can be can be decisive in breaking the fragile line between health and disease (Caldas \& Berterö, 2012). The abrupt appearance of the disease is reported in studies that consider that there may be a clash of the past with the present. This makes it difficult for patients to understand how they have reached this point. The diagnosis and treatment are perceived as sudden, overwhelming, and unknown, leading them to consider that this admission to dialysis was abrupt and unexpected (Gullick et al., 2016; da Cruz et al., 2016; Nagpal et al., 2017).

Being present and not seeing it, its manifestation in time, and the symptoms give clues that patients do not recognize due to ignorance. Some studies explain that anaemia, proteinuria, and oedema occur in CKD, but go unnoticed and are not, evidently, leading them to ignore their disease (Lin et al., 2013; Nagpal et al., 2017; Saunders et al., 2015). Those who are sick and young in age have the greatest difficulties in accepting changes in their self-image. This affects their social interaction, particularly due to the presence of catheters, arteriovenous fistula, and the inability to handle activities of daily living, all considered to be stressful factors (Kazemi et al., 2011). 
Corporeity allows us to identify how the body experiences the phenomenon, becoming the way it is felt, perceived, and touched by the body (Van Manen, 2014). The deteriorated body and the alteration of sexual life are the subthemes that emerged around this existential corporality. In this category, this study described the deterioration of the body which influenced the lives of the participants. It led them to increased dependence, self-pity, depression, and changes in their state, in their needs and capacities that produced overload and deterioration in their quality of life (McQuoid et al., 2015; Niu \& Liu, 2017). CKD and HD affect the sexuality of people significantly, increasing the impact it causes on those who suffer (Sabanciogullari et al., 2015). The descriptions from the participants of this study show how men and women experience loss of sexual interest, not only because of the disease and treatment, but also magnified by the presence of the peritoneal catheter (Al Nazly et al., 2013; Algarra et al., 2016).

In relation to materiality, we reflect on how "intramundane entities" (Heidegger, 1974) take on meaning in the analyzed phenomenon. This is how the impact on the economic situation is described. Al Nazly et al. (2013) found that the symptoms of the disease have a negative influence on working life. The disease itself produces limitations that cause a detrimental impact on patients' working life, leading them to financial difficulties. In many cases they are disabled, moving them away from work that can be a mechanism to continue feeling normal in their lives (Chiaranai, 2016; Cruz et al., 2016; Gullick et al., 2016).

With regards to spatiality, McQuioid et al. (2015) described as one that has Cartesian properties with universal coordinates and distances, but in this reflection, it is not physical space. On the contrary, it is delineated in the way that space takes meaning for the phenomenon studied (Van Manen, 2014). Heidegger (1974) explained, "the spatiality of man is something inherent in his bodily being ..." founded "on his corporeality" (p. 70). For that reason, it is taken as the meaning of a place or event within human experience. This raises related sub-themes, life changes, sadness, and depression. In this sense, several studies describe how people with CKD, especially young people experience shock, cholera, indignation, isolation, and depression in the face of the disease (Cruz et al., 2016; de Carvalho et al., 2012; Monaro et al., 2014). Others describe how they feel unable to perform their roles, restrictions on their lifestyle, and work changes affecting the balance between illness and normalcy, feeling that their life changes (Chatrung et al., 2015). The analysis around the existential allows for an understanding of the experience lived from a holistic view, where each of them become important aspects of life. The person experiences and 
lives the disease as something unique and tries to build their reality around it, in a deeply personal and unique way (Van Manen 2014).

\section{CONCLUSION}

This study exposeded how people are able to reveal their experience during interviews, describing significant aspects for them in the disease process. Existentiality allows patients with CKD to construct meanings around them that brings them closer to a reality that can remain hidden before the eyes of the nurses in charge of their care.

The meanings attributed to this experience allow researchers to recognize how CKD occurs unexpectedly and abruptly. It manifests itself in time so that patients indicate that there were signs, but these were ignored because they could still maintain their daily lives. Likewise, for young people, it is a point of breakdown in their life that hinders their social interactions and marks a social stigma for their own changes in their body image. The body can be damaged by the disease, transforming the view of how the person experiences his sick body.

The support of family and friends takes on a special meaning. Support is a way of moving forward with life, allowing those with CKD to face the dependence experienced because of the illness and treatment.

On the other hand, the fear of becoming a burden for their family and the fear of abandonment remains veiled for their family and social group, recognizing that they suffer from a chronic illness of a terminal nature.

Substantial changes occur in people's lives from the moment of diagnosis that lead them to rethink their lives, provoking feelings of depression, anguish, fear, and suicidal ideas that can be linked to the loss of control in their life. Having support, comfort and reflecting on this situation are important mechanisms to assume the disease with responsibility.

Disease and treatment have an economic impact; the inability to work, dependence, and becoming an economic burden leads them to lose the "normality" that they wish to experience in order to face the disease and treatment. It is important to design participatory education strategies, based on the individual needs of people with CKD, which can help mitigate the multiple changes and adjustments that must be made in their lives. 
Strengthening in the nursing curriculum, specifically the component of caring for people in chronic situations, to favor the identification of populations at risk, increasing knowledge of prevention strategies of CKD, and applying specific protocols for the care of people in this condition would help with their care. In this research, the use of a phenomenologically hermeneutical approach based on Van Manen's theoretical proposal, and with the help of the existentials as interpretive guides, revealed meaning of the lived experience of people in chronic situations or in different situations of health or illness.

Acknowledgements. I express my deep appreciation to the people who participated in this study, to the Transplantation Unit that provided the database with the information, and Surcolombiana University.

\section{REFERENCES}

Al Nazly, E., Ahmad, M., Musil, C., \& Nabolsi, M. (2013). Hemodialysis stressors and coping strategies among Jordanian patients on hemodialysis: A qualitative study. Nephrology Nursing Journal, 40(4), 321-327. https://doi.org/10.1080/13548506.2014.952239

Algarra, A., Salazar, N., Parra, K., da Cruz, V., Tagliamento, G., \& Wanderbroocke, A. C. (2016). The maintenance of work life by chronic kidney patients in hemodialysis treatment: An analysis of the meanings of work. Revista de La Sociedad Espanola de Enfermeria Nefrologica, 25(2), 154-163. https://doi.org/10.1590/S0104-12902016155525

Caldas, C. P., \& Berterö, C. (2012). A concept analysis about temporality and its applicability in nursing care. Nursing Forum, 47(4), 245-252. https://doi.org/10.1111/j.1744-6198.2012.00277.x

Calvey, D., \& Mee, L. (2011). The lived experience of the person dependent on haemodialysis. Journal of Renal Care, 37(4), 201-207. https://doi.org/10.1111/j.1755-6686.2011.00235.x

Chatrung, C., Sorajjakool, S., \& Amnatsatsue, K. (2015). Wellness and religious coping among Thai individuals living with chronic kidney disease in Southern California. Journal of Religion and Health, 54(6), 2198-2211. https://doi.org/10.1007/s10943-014-9958-4

Chiaranai, C. (2016). The lived experience of patients receiving hemodialysis treatment for end-stage renal disease: A qualitative study. Journal of Nursing Research, 24(2), 101-108. https://doi.org/10.1097/jnr.000000000000010

Campos, C, \& Turato, E. (2010). Tratamento hemodialítico sob a ótica do doente renal: estudo clínico qualitativo [Hemodialysis treatment as perceived by the renal patient: clinical qualitative study]. Journal Brazilian de Enfermagem, 63(5), 799-805. http://dx.doi.org/10.1590/S0034-71672010000500017

da Cruz, V., Tagliamento, G., \& Wanderbroocke, A. (2016). A manutenção da vida laboral por doentes renais crônicos em tratamento de hemodiálise: Uma análise dos significados do trabalho [The maintenance of work life by chronic kidney patients in hemodialysis treatment: an analysis of the meanings of work]. Saúde e Sociedade , 25(4), 1050-1063. https://doi.org/10.1590/s0104-12902016155525

de Carvalho, M., Moreira, M., \& Nunes, C. (2012). Estágios do pesar nos discursos de jovens em tratamento renal substitutivo [Stages of grief in the discourse of young people in renal replacement therapy]. Revista Enfermagem, 20(2), 203-208. https://www.e-

publicacoes.uerj.br/index.php/enfermagemuerj/article/view/4052 
dos Santos, F. K., \& Valadares, G. (2013). Conhecendo as estratégias de ação e interação utilizadas pelos clientes para o enfrentamento da diálise peritoneal [Investigating the action and interaction strategies that patients use to cope with peritoneal dialysis]. Escola Anna Nery, 17(3), 423-431. http://dx.doi.org/10.1590/S1414-81452013000300004

Ene-lordache, B., Perico, N., Bikbov, B., Carminati, S., Remuzzi, A., Perna, A., \& Remuzzi, G. (2016). Chronic kidney disease and cardiovascular risk in six regions of the world (ISN-KDDC): A cross-sectional study. The Lancet Global Health, 4(5), e307-e319. https://doi.org/10.1016/S2214-109X(16)00071-1

Finlay, L. (2002). Negotiating the swamp: the opportunity and challenge of reflexivity in research practice. Qualitative Research, 2(2), 209-230. https://doi.org/10.1177/146879410200200205

Gill, P. (2012). Stressors and coping mechanisms in live-related renal transplantation. Journal of Clinical Nursing, 21(11-12), 1622-1631. https://doi.org/10.1111/j.1365-2702.2012.04085.x

Gullick, J., Monaro, S., \& Stewart, G. (2016). Compartmentalising time and space: A phenomenological interpretation of the temporal experience of commencing haemodialysis. Journal of Clinical Nursing, 26(2122), 3382-3395. https://doi.org/10.1111/jocn.13697

Heidegger, M. (1974). Being and time. (F. de cultura Economica, Ed.) Fondo de Cultura Económica.

Kazemi, M., Nasrabadi, A., Hasanpour, M., Hassankhani, H., \& Mills, J. (2011). Experience of Iranian persons receiving hemodialysis: A descriptive, exploratory study. Nursing \& Health Sciences, 13(1), 88-93. https://doi.org/10.1111/j.1442-2018.2011.00586.x

Lam, L. W., Lee, D., \& Shiu, A. (2014). The dynamic process of adherence to a renal therapeutic regimen: Perspectives of patients undergoing continuous ambulatory peritoneal dialysis. International Journal of Nursing Studies, 51(6), 908-916. https://doi.org/10.1016/j.jinurstu.2013.10.012

Lin, C., Chen, M., Hsieh, H., \& Chang, S. (2013). Illness representations and coping processes of Taiwanese patients with early-stage chronic kidney disease. Journal of Nursing Research, 21(2), 120-128. https://doi.org/10.1097/jnr.0b013e3182921fb8

Lin, C., Han, C., \& Pan, I. (2015). A qualitative approach of psychosocial adaptation process in patients undergoing long-term hemodialysis. Asian Nursing Research, 9(1), 35-41. https://doi.org/10.1016/j.anr.2014.10.007

Lincoln, Y. S., \& Guba, E. G. (1985). Naturalistic inquiry. SAGE.

McQuoid, J., Welsh, J., Strazdins, L., Griffin, A. L., \& Banwell, C. (2015). Integrating paid work and chronic illness in daily life: A space-time approach to understanding the challenges. Health and Place, 34(2015), 83-91. https://doi.org/10.1016/j.healthplace.2015.04.001

Monaro, S., Stewart, G., \& Gullick, J. (2014). A "lost life": Coming to terms with haemodialysis. Journal of Clinical Nursing, 23(21-22), 3262-3273. https://doi.org/10.1111/jocn.12577

Nagpal, N., Boutin-Foster, C., Melendez, J., Kubiszeswki, P., Uehara, K., Offidani, E., Faussett, Z., Chen, R., Redel, C., Waltrous, C., \& Smith, B. (2017). Experiences of patients undergoing dialysis who are from ethnic and racial minorities. Journal of Renal Care, 43(1), 29-36. https://doi.org/10.1111/jorc.12185

Niu, H., \& Liu, J. (2017). The psychological trajectory from diagnosis to approaching end of life in patients undergoing hemodialysis in China: A qualitative study. International Journal of Nursing Sciences, 4(1), 2933. https://doi.org/10.1016/j.ijnss.2016.10.006

Palmer, S. C., Hanson, C. S., Craig, J. C., Strippoli, G. F. M., Ruospo, M., Campbell, K., Johnson, D. W., \& Tong, A. (2015). Dietary and fluid restrictions in CKD: A thematic synthesis of patient views from qualitative studies. American Journal of Kidney Diseases, 65(4), 559-573. https://doi.org/10.1053/j.ajkd.2014.09.012

Patton, M. Q. (2002). Qualitative evaluation methods and research methods. SAGE. 
Sabanciogullari, S., Yilmaz, F., Gngr, F., Sylemez, S., \& Benli, R. (2015). Sexual function in patients with chronic renal failure on hemodialysis and its effects on patients' perception of health and life satisfaction. Sexuality \& Disability, 33(2), 175-186. https://doi.org/10.1007/s11195-015-9398-4

Saunders, M. R., Kim, S. D., Patel, N., Meltzer, D. O., \& Chin, M. H. (2015). Hospitalized patients frequently unaware of their chronic kidney disease. Journal of Hospital Medicine, 10(9), 619-622. https://doi.org/10.1002/jhm.2395

Schaepe, C., \& Bergjan, M. (2015). Educational interventions in peritoneal dialysis: A narrative review of the literature. International Journal of Nursing Studies, 52(4), 882-898. https://doi.org/10.1016/j.jpurstu.2014.12.009

Van Manen, M. (2014). Phenomenology of practice: meaning-giving methods in phenomenological research and writing. Left Coast Press. 